\title{
Facile synthesis of highly porous N-doped carbon nanosheets with silica nanoparticles for ultra-high capacitance supercapacitors
}

\author{
Arthi Gopalakrishnan ${ }^{1,2}$, Aimin $\mathrm{Yu}^{2}$, Sushmee Badhulika ${ }^{1 *}$
}

${ }^{1}$ Department of Electrical Engineering, Indian Institute of Technology Hyderabad, Hyderabad 502285, India

${ }^{2}$ Department of Chemistry \& Biotechnology, Swinburne University of Technology, Hawthorn, Vic 3122, Australia.

*Corresponding author: E-mail: sbadh@iith.ac.in; Phone: 040-23018443, Fax- 04023016032.
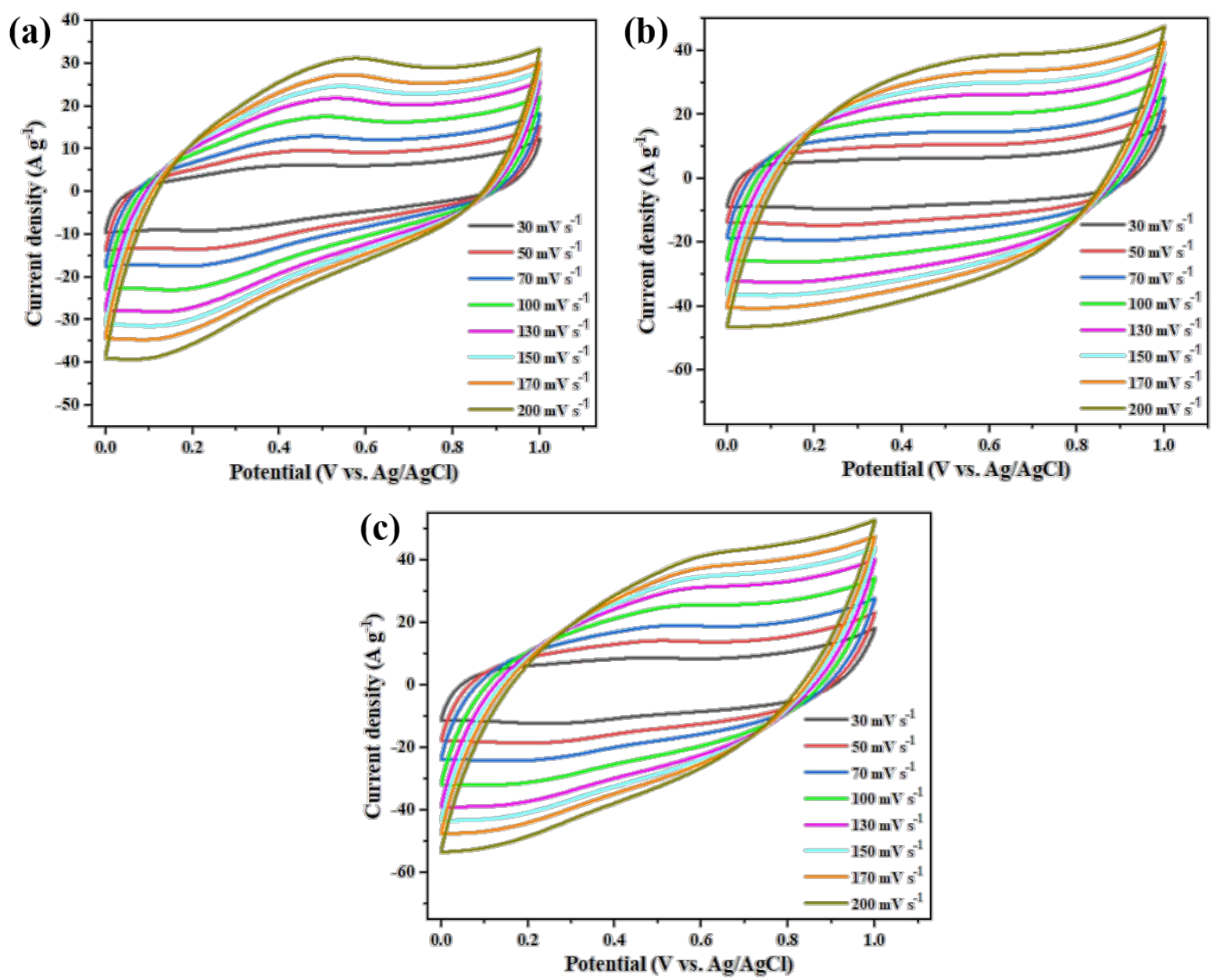
Figure S1: CV profiles of (a) AOC 700; (b) AOC 800; and (c) AOC 900 in three-electrode system.
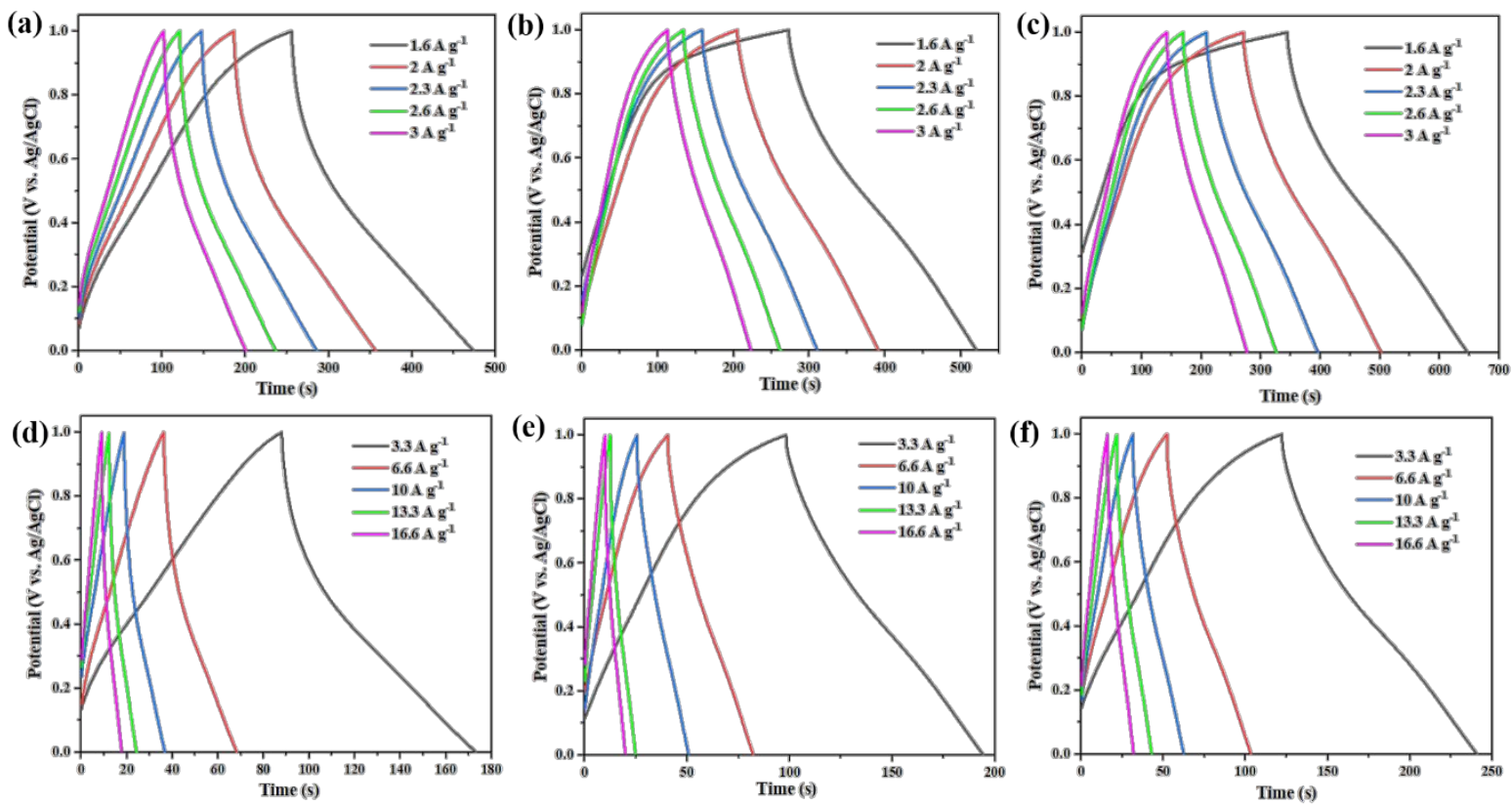

Figure S2: GCD profiles of AOC 700, 800 \& 900 samples in three-electrode cell (a-c) at low current densities; (d-f) at high current densities. 

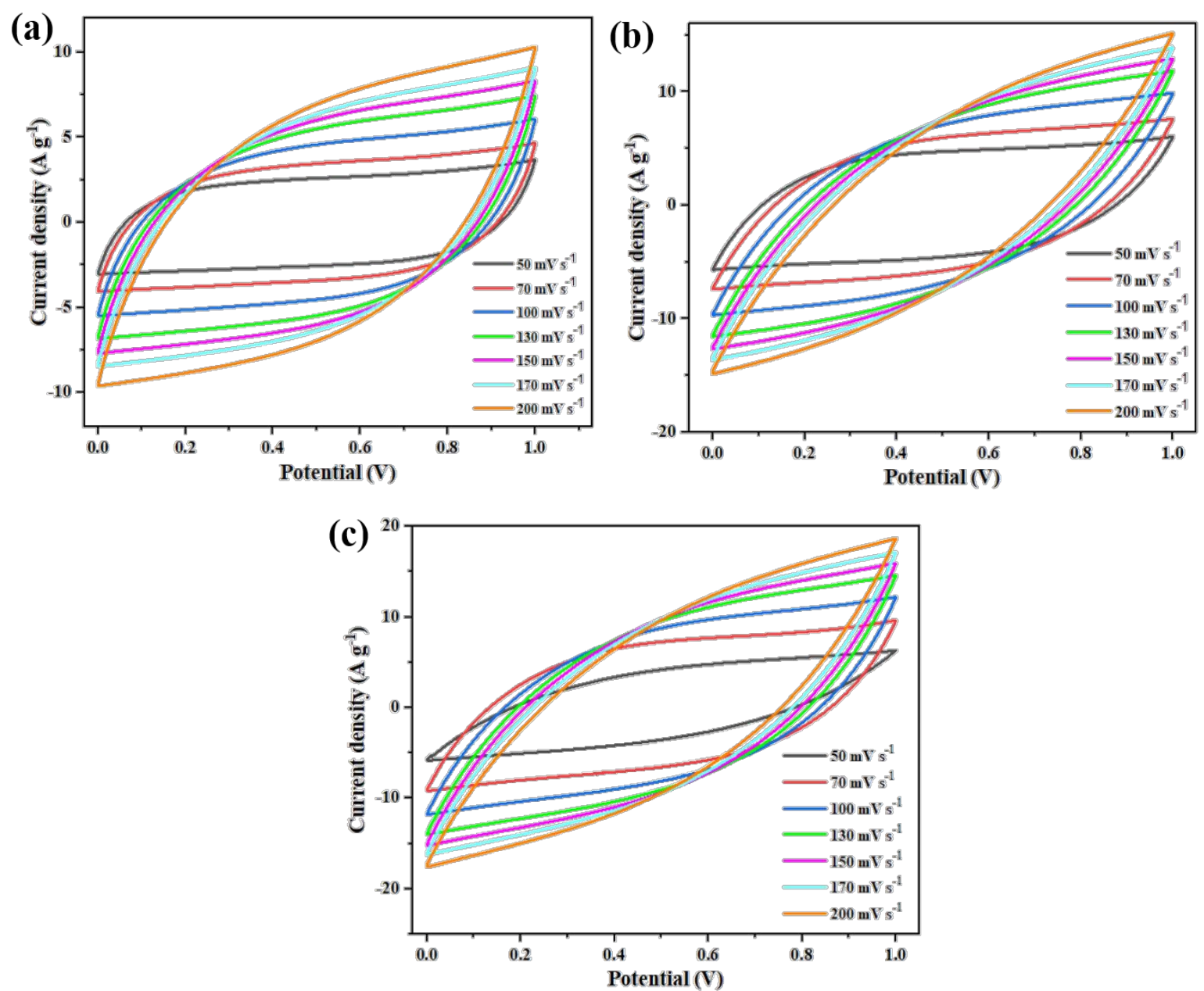

Figure S3: CV profiles of (a) AOC 700; (b) AOC 800; (c) AOC 900 in two-electrode symmetric cell. 

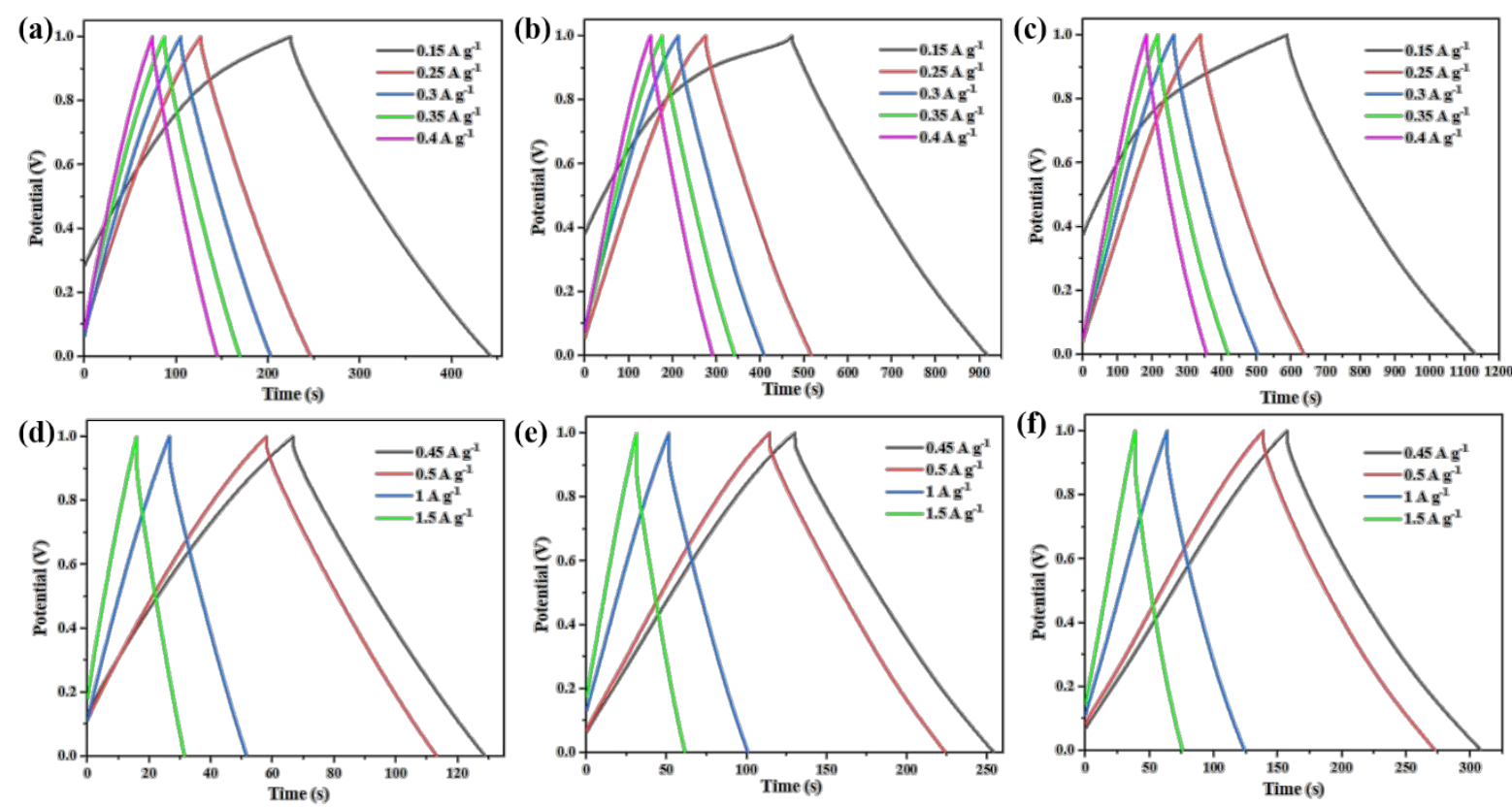

Figure S4: GCD profiles of AOC 700, 800 \& 900 samples in two-electrode cell (a-c) at low current densities; (d-f) at high current densities. 